

PLANNING MALAYSIA:

Journal of the Malaysian Institute of Planners

VOLUME 16 ISSUE 1 (2018), Page $38-49$

\title{
SOCIAL CAPITAL AMONG AGEING RESIDENTS OF HOUSING COMPLEXES IN SUBURBAN TOKYO: THE CASE OF HARAICHI- DANCHI AND OYAMADAI-DANCHI IN AGEO CITY
}

\author{
Nadhirah Nordin $^{1} \&$ Hitoshi Nakamura ${ }^{2}$ \\ ${ }^{1,2}$ Graduate School of Engineering and Science \\ SHIBAURA INSTITUTE OF TECHNOLOGY
}

\begin{abstract}
Globally, developed nations such as Japan are currently facing an ageing population. The health and social care system in the living environment for the elderly population in Japan must engender strong social ties and social networks that can connect the elderly people and promote active ageing. This research aims to identify the extent of social capital among the ageing population in Haraichidanchi and Oyamadai-danchi, which are housing complexes located in Ageo City, a suburb of Tokyo. This article focuses on residents in the 60s and 70s age groups. A questionnaire survey was conducted and was divided into three parts which include the basic attributes of the residents, the elements of bonding social capital and bridging social capital. Then, cross-tabulations were done between the age groups and both the social capital categories. Next, chi-square and further post-hoc analyses were conducted to determine the strongest association between the variables. The results show a significant association between the 60s and 70s age groups for both bonding and bridging social capital. The variation of results may be influenced by the physical environment of the housing complexes in which they are currently living.
\end{abstract}

Keyword: aging society, suburban housing complex, social capital 
PLANNING MALAYSIA

Journal of the Malaysia Institute of Planners (2018)

\section{INTRODUCTION}

Japan, as one of the world's developed nations, has seen the percentage of its elderly population (aged 65 and older) increased from $19.8 \%$ in 2005 to $26.3 \%$ in 2015 (World Bank, 2016), thus making it the highest ratio of ageing population in the world. To cater such trend, a shift towards focusing on planning for the ageing population in all sectors of development such as social, health and even the physical built environment is needed.

This research aims to identify the extent of social capital among the ageing population in Haraichi-danchi and Oyamadai-danchi, which are housing complexes located in Ageo City, a suburban area near Tokyo. Social capital in the ageing society is important to promote active ageing (Aminjafari, Aghajani, $\&$ Hashemianfar, 2016). Thus, it is important to create strong social capital, which can be further understood by examining the three main domains listed by Putnam (2000), which are bonding, bridging and linking social capital. Bonding is associated with the relationship between the community members with the same demographic characteristics and socio-financial positions (Babaei, Ahmad, \& Gill, 2012), which often includes family and friend relationships (Twigger-Ross, Bonaiuto, \& Breakwell, 2003). Bridging social capital on the other hand is based on the connections between community members that do not have similar characteristics such as age, ethnicity; and education (Szreter \& Woolcock, 2004). Lastly, Babaei et al. (2012) define linking social capital as the linking relationship among groups or individuals with power, authority, and access to key resources. This research focuses only on two elements of social capital which are bonding and bridging.

The economic growth in Japan during the post-war period has stimulated the development of suburban residential communities, mainly affordable housing complexes called danchi, which are usually 5-storeys. During that time, many danchi were created to accommodate the growing population especially working people among the $30 \mathrm{~s}-40$ s who started to have family. Today, they aged 65 years old and above, thus belonging to the ageing group. Recently, increasing trends of diminishing social structure among the working age group because of their commitment to working has led to a decreasing number in nuclear families and less social engagements with neighbours (Gouda \& Okamoto, 2012). Following this, they will most likely experience social isolation after retirement. Hence, the scope of social aspect among the community in the neighbourhood environment especially among elderly people has become the main topic to be investigated.

The study areas of this research consist of two housing complexes, Haraichi-danchi and Oyamadai-danchi, as shown in Figure 1. These are public housing complexes constructed and managed by the Urban Renaissance (UR) agency in Japan. Located in Saitama Prefecture, currently there are approximately 2,781 residents and 1,532 households in Haraichi-danchi and approximately 
Nadhirah Nordin \& Hitoshi Nakamura

Social Capital Among Ageing Residents of Housing Complexes in Suburban Tokyo: The Case of Haraichi-Danchi and

Oyamadai-Danchi in Ageo City

3,005 residents and 1,741 households in Oyamadai-danchi. The two housing complexes were chosen as the study areas because the percentage of elderly residents out of the total residents were quite high, about $35.3 \%$ and $41.2 \%$, respectively. Danchi were usually constructed without elevator but outer staircases to connect two apartment units on each floor (Figure $2 \& 3$ ). However, elevators were installed later to cater the needs of the elderly residents in some chosen housing blocks. The difference between both housing complexes is that the neighbourhood environment of Haraichi-danchi is divided into two parts by an arterial highway; and connected by a pedestrian bridge, whereas the neighbourhood environment of Oyamadai-danchi is clustered together. Besides, the neighbourhood associations in both housing complexes have close link with private institutions such as Shibaura Institute of Technology (SIT) in order to promote social participation and neighbourhood liveability. This has encouraged SIT to set up a "Satellite Lab of Ageo" in Haraichi-danchi (Figure 4).

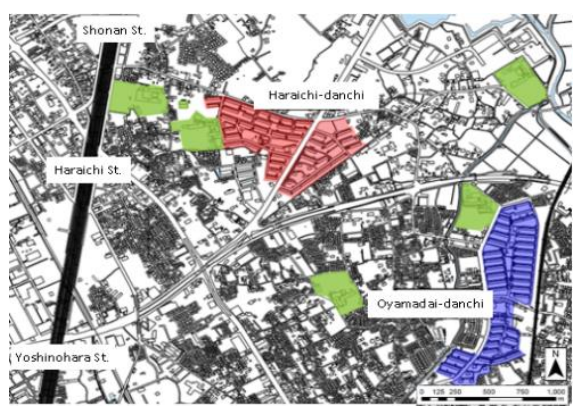

Figure 1: Map of Haraichi-danchi and Oyamadai-danchi in Ageo City

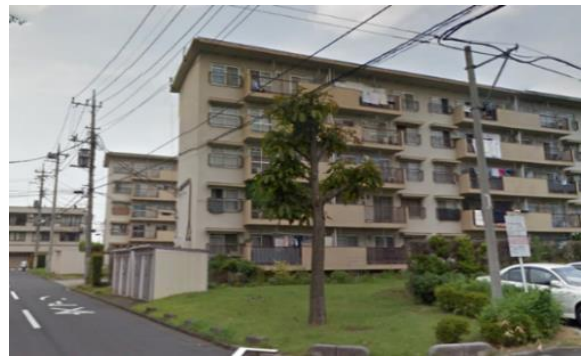

Figure 3: Five-storey apartment blocks in Haraichi-danchi

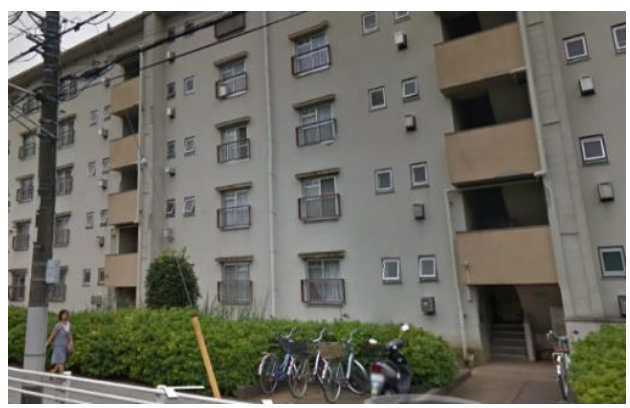

Figure 2: Stairs connecting apartment units in each floor in Oyamadai-danchi

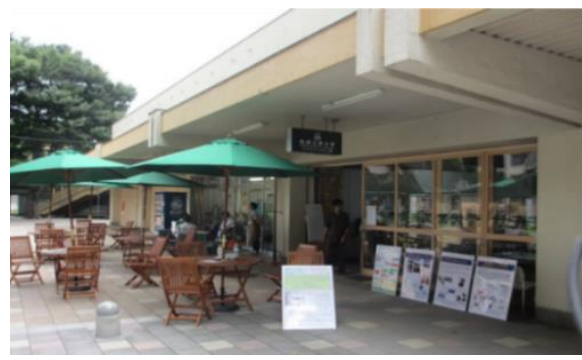

Figure 4: "Satellite Lab of Ageo" in Haraichi-danchi established by SIT

\section{METHODOLOGY}

For this research, the age groups involved were the 60s and 70s, which are considered as young-old and old-old age groups respectively. The age group of 80 s was not included because of the limited number of respondents in this age group in both housing complexes. A questionnaire survey was distributed in 
PLANNING MALAYSIA

Journal of the Malaysia Institute of Planners (2018)

November 2015 to the households in Haraichi-danchi and Oyamadai-danchi respectively. The number of respondents in Haraichi-danchi was 593 people and 543 people in Oyamadai-danchi, with an effective reply ratio of approximately $38.6 \%$ for Haraichi-danchi and 31.3\% for Oyamadai-danchi. The questionnaire was divided into three parts: the basic attributes of the residents including their current knowledge on disaster prevention; their participation in neighbourhood activities, including disaster prevention training; and their relationships with their neighbours. The questionnaire survey were then restructured to adhere to the context of bonding and bridging social capital, which were divided into three parts; the basic attributes of residents, the elements of bonding social capital and bridging social capital.

In the analysis stage of the research, cross-tabulation was done between the two age groups and the social capital attributes, which are bonding and bridging. Then, chi-square analyses were conducted to determine whether the two attributes were associated. Next, further analyses of post-hoc tests were done to determine the strongest associations between the attributes by calculating the adjusted residuals obtained from the Pearson chi-square values in each cell. The criteria to choose the most significant association were adjusted residual values which should be higher than the z-values and only positively adjusted residual values were taken into account.

\section{FINDINGS}

In terms of the basic attributes of the respondents, Figure 5 shows men as the majority group of respondents consisting of about $59.9 \%$ and $58.8 \%$, whereas women consist of about $39.0 \%$ and $40.7 \%$ in Haraichi-danchi and Oyamadaidanchi respectively. Figure 6 shows the proportion of residents based on age range, where people in their $60 \mathrm{~s}$ were the majority respondents, which were about $37.1 \%$ and $44.38 \%$; and the second largest group which were people in their 40s - 50s comprising of $29.01 \%$ and $28.36 \%$ of the total population in Haraichidanchi and Oyamadai-danchi respectively. People from the 60s and 70s age groups are regarded as elderly in this research, which makes them the highest percentage of residents living in both housing complexes, including people in the 70s which are about $20.4 \%$ and $20.44 \%$ in Haraichi-danchi and Oyamadai-danchi respectively. It was noted that the people below 30s age group are mainly young adults and workers.

Figure 7 shows about $44.7 \%$ and $48.6 \%$ of the respondents have lived more than 31 years in Haraichi-danchi and Oyamadai-danchi. Regarding family structure, the majority of the residents were living together with their families, which were about $64.15 \%$ and $85.0 \%$ in both housing complexes respectively. The category of single person in Haraichi-danchi was around $35.84 \%$, but less in Oyamadai-danchi which was around $15.0 \%$, as can be seen in Figure 8. Figure 9 shows the respondents' occupations in both housing complexes where a majority 
Nadhirah Nordin \& Hitoshi Nakamura

Social Capital Among Ageing Residents of Housing Complexes in Suburban Tokyo: The Case of Haraichi-Danchi and

Oyamadai-Danchi in Ageo City

of them were unemployed, consisting of about $64.1 \%$ and $58.9 \%$ in Haraichidanchi and Oyamadai-danchi respectively. To summarise, most of them were permanent residents living with families where they have lived for a long time in the housing complexes and were unemployed.



Figure 5: Proportion of residents by gender in both housing complexes

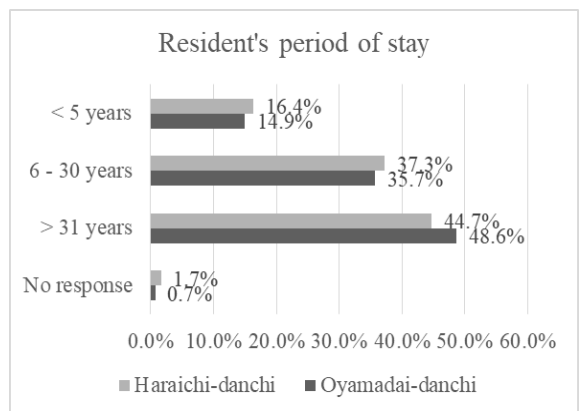

Figure 7: Proportion of residents by period of stay in both housing complexes

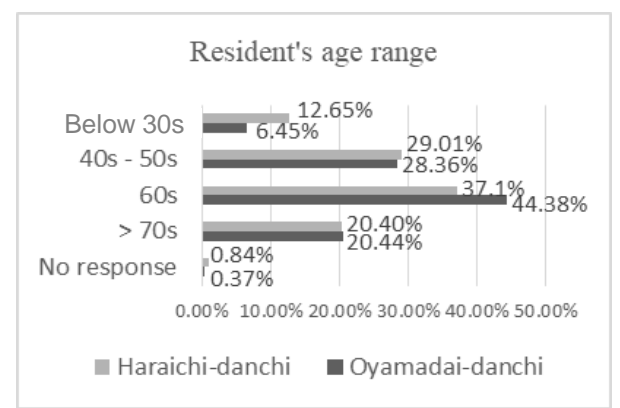

Figure 6: Proportion of residents by age range in both housing complexes

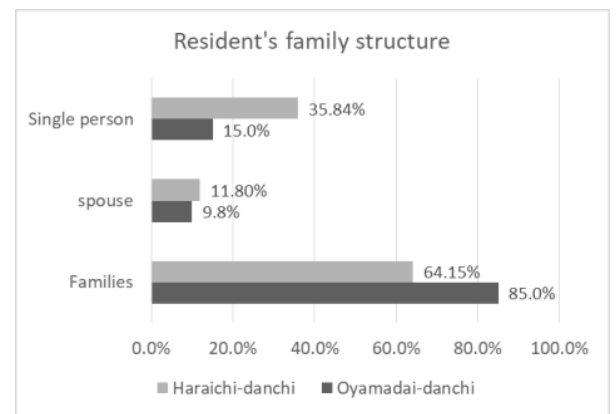

Figure 8: Proportion of residents by family structure in both housing complexes



Figure 9: Proportion of residents' occupations in both housing complexes 
PLANNING MALAYSIA

Journal of the Malaysia Institute of Planners (2018)

Table 1 shows the classification of social capital for bonding and bridging included in the questionnaire survey as well as the majority percentages for each of the attributes.

Table 1: Classification of social capital context from the questionnaire survey

\begin{tabular}{|c|c|}
\hline Bonding Social Capital & Bridging Social Capital \\
\hline $\begin{array}{l}\text { Presence of reliable person } \\
\text { - No one } \\
(\mathrm{H}=42.3 \%, \mathrm{O}=36.5 \%)\end{array}$ & $\begin{array}{l}\text { Participation in neighbourhood association } \\
\text { - Join }(\mathrm{H}=71.84 \%, \mathrm{O}=88.21 \%)\end{array}$ \\
\hline $\begin{array}{l}\text { Relationship with } \\
\text { neighbours } \\
\text { - No trouble } \\
(\mathrm{H}=68.5 \%, \mathrm{O}=71.1 \%)\end{array}$ & $\begin{array}{l}\text { Recognition on neighbourhood association activities } \\
\text { - Knows to a certain extent }(\mathrm{H}=63.8 \%, \mathrm{O}=69.2 \%)\end{array}$ \\
\hline $\begin{array}{l}\text { Communication exchanges } \\
\text { between neighbours } \\
\text { - Chatting \& greeting } \\
(\mathrm{H}=71.9 \%, \mathrm{O}=80.1 \%)\end{array}$ & $\begin{array}{l}\text { Necessity to join neighbourhood association } \\
\text { - Necessary }(\mathrm{H}=43.2 \%, \mathrm{O}=57.5 \%)\end{array}$ \\
\hline $\begin{array}{l}\text { Necessity for } \\
\text { communication exchanges } \\
\text { - Some are necessary } \\
(\mathrm{H}=70.7 \%, \mathrm{O}=74.8 \%)\end{array}$ & $\begin{array}{l}\text { Reasons for not joining the neighbourhood association } \\
\text { - Burden to be stairs committee } \\
(\mathrm{H}=28.8 \%, \mathrm{O}=28.9 \%) \\
\text { Problems of neighbourhood association } \\
\text { - Low awareness on the association importance } \\
(\mathrm{H}=26.3 \%, \mathrm{O}=28.7 \%) \\
\text { Expectations for neighbourhood association activities } \\
\text { - Calm and peaceful activities } \\
(\mathrm{H}=67.3 \%, \mathrm{O}=78.5 \%) \\
\text { Ways to activate the neighbourhood association } \\
\text { - Increase members in the association } \\
\text { (H=48.6\%, } \mathrm{O}=60.4 \%) \\
\text { Experience of stairs committee* } \\
\text { - Yes }(\mathrm{H}=56.5 \%, \mathrm{O}=81.4 \%) \\
\text { Participation in volunteering activities } \\
\text { - Participate if convenient }(\mathrm{H}=41.3 \%, \mathrm{O}=47.0 \%) \\
\text { Participation in disaster prevention training } \\
\text { - Have not participated }(\mathrm{H}=65.6 \%, \mathrm{O}=32.8 \%) \\
\text { Awareness on voluntary disaster prevention training } \\
\text { - Did not know (H=70.0\%, } \mathrm{O}=28.2 \%)\end{array}$ \\
\hline
\end{tabular}

*Small floor committee in each housing blocks

$\mathrm{H}$ : Haraichi-danchi; O: Oyamadai-danchi

The bonding social capital, which means the relationship between the community members with the same demographic features, in both housing complexes can be described by three characteristics: having no one to rely on even though they have daily social contacts, thinking that communication 
Nadhirah Nordin \& Hitoshi Nakamura

Social Capital Among Ageing Residents of Housing Complexes in Suburban Tokyo: The Case of Haraichi-Danchi and

Oyamadai-Danchi in Ageo City

exchanges are necessary and being on good terms with their neighbours at the present time. On the other hand, bridging social capital, which means relationship between community members that do not have similar characteristics, can be described by three characteristics: majority of residents in both housing complexes joined the neighbourhood association, knew to a certain extent about the association's activities and thought that it is necessary for the associations to exist in the housing complexes. The reason people did not join the association was due to the obligation to be on the stairs committee and they thought that the problem for low participation was because of low awareness among the residents. Moreover, the residents expected the neighbourhood association to conduct peaceful and calm activities so that more people would have the desire to become a member of the neighbourhood association. Even so, most of them had the experience becoming part of the stairs committee and wanted to participate in volunteering activities if the time was convenient, but significant percentages showed that residents in Haraichi-danchi did not participate in the disaster prevention training because more than half of them were unaware about the voluntary disaster prevention training.

\section{MAIN RESULTS}

Based on Table 2, the analyses show significant associations for both bonding and bridging among various age groups in Haraichi-danchi. For bonding social capital, the people in the 60s and 70s age group tended to have at least one person to rely on and greeted their neighbours on a daily basis. For bridging social capital in Haraichi-danchi, those in the 60s age group joined the neighbourhood association, had experienced being members of the stairs committee and had the desire to participate in disaster prevention training if they had spare time. For those in the 70s age group, even though there was no significant motivation found for joining the neighbourhood association, they tended to know very well about the activities conducted by the association. They thought that it was necessary to join the association and had experienced being members of the stairs committee.

Table 3 shows significant associations for both bonding and bridging among various age groups in Oyamadai-danchi. No significant association was shown through bonding among the 60s age group but for the 70s age group, they tended to have several reliable persons and chatted with their neighbours daily. For bridging social capital in Oyamadai-danchi shown in Table 3, those in the 60s age group expected the neighbourhood association to organize peaceful activities and to enhance welfare activities. They also had some experience of being the stairs committee members and participated in volunteering. Different to the people in the 70s age group, they expected the neighbourhood association to organize disaster or crime prevention activities and would like to join the auspicious celebration. 
PLANNING MALAYSIA

Journal of the Malaysia Institute of Planners (2018)

Based on the main results of the analyses, it can be concluded that most people in their 60s and 70s tended to show some significant bonding and bridging social capital; however, this was not always the case for both Haraichi-danchi and Oyamadai-danchi. The major similarities among adults in the two housing complexes were that the people in their 60s tended to participate more in bridging activities and those in their 70s tended to have several people to rely on for bonding social capital. On the contrary, the major differences between the two housing complexes were that the people in their 70s in Haraichi-danchi tended to be aware of the community activities, even though they did not join the association, whereas the people in their 70s in Oyamadai-danchi did not show any significant association for bridging social capital.

Table 2: Summary of findings for both social capital in Haraichi-danchi

\begin{tabular}{|c|c|c|c|}
\hline $\begin{array}{l}\text { Housing } \\
\text { Complexes }\end{array}$ & $\begin{array}{l}\text { Age } \\
\text { Groups }\end{array}$ & $\begin{array}{l}\text { Bonding Social } \\
\text { Capital }\end{array}$ & Bridging Social Capital \\
\hline \multirow{15}{*}{$\begin{array}{l}\text { Haraichi- } \\
\text { danchi }\end{array}$} & \multirow{8}{*}{$\begin{array}{l}\text { Below } \\
30 \mathrm{~s}\end{array}$} & \multirow{5}{*}{$\begin{array}{l}\text { Communication } \\
\text { exchanges are } \\
\text { based on family } \\
\text { relationship } \\
\text { (R: } 3.60, \text { Z: } 2.96)\end{array}$} & Does not join N.A. (R: $13.83, \mathrm{Z}: 2.73$ ) \\
\hline & & & $\begin{array}{l}\text { Know little about activities done by N.A. } \\
\text { (R: } 6.11, \mathrm{Z}: 3.02)\end{array}$ \\
\hline & & & $\begin{array}{l}\text { Thought that N.A. is unnecessary } \\
\text { (R: } 3.65, \mathrm{Z}: 2.77 \text { ) }\end{array}$ \\
\hline & & & $\begin{array}{l}\text { Problems of N.A. is young people and } \\
\text { workers are hard to participate } \\
\text { (R: } 5.04, \mathrm{Z}: 2.73 \text { ) }\end{array}$ \\
\hline & & & $\begin{array}{l}\text { Expectation for N.A. activities is to } \\
\text { provide child rearing support } \\
\text { (R: } 4.71, \mathrm{Z}: 2.73 \text { ) }\end{array}$ \\
\hline & & \multirow{3}{*}{$\begin{array}{l}\text { Trouble with } \\
\text { neighbors in the } \\
\text { past } \\
\text { (R: } 3.12, \mathrm{Z}: 2.87 \text { ) }\end{array}$} & $\begin{array}{l}\text { Have no experience in stairs committee } \\
\text { (R: } 6.90, \mathrm{Z}: 2.73 \text { ) }\end{array}$ \\
\hline & & & $\begin{array}{l}\text { Do not want to join volunteering } \\
\text { (R: } 3.40, \mathrm{Z}: 2.87 \text { ) }\end{array}$ \\
\hline & & & $\begin{array}{l}\text { Have not participated in D.P. training } \\
\text { (R: } 3.02, \mathrm{Z}: 2.81 \text { ) }\end{array}$ \\
\hline & $40 \mathrm{~s}$ & \multirow{3}{*}{$\begin{array}{l}\text { Trouble with } \\
\text { neighbors in the } \\
\text { past } \\
\text { (R: } 5.31, \mathrm{Z}: 2.87 \text { ) }\end{array}$} & Does not join N.A. (R: 3.58, Z: 2.73) \\
\hline & $50 \mathrm{~s}$ & & $\begin{array}{l}\text { Activities of N.A. that they would like to } \\
\text { join is summer festival (R: } 3.38, \mathrm{Z}: 2.73 \text { ) }\end{array}$ \\
\hline & & & $\begin{array}{l}\text { Have not participated in D.P. training } \\
(\mathrm{R}: 3.68, \mathrm{Z}: 2.81 \text { ) }\end{array}$ \\
\hline & \multirow[t]{4}{*}{$60 \mathrm{~s}$} & $\begin{array}{l}\text { 1reliable person } \\
\text { (R: } 5.38, \mathrm{Z}: 2.96)\end{array}$ & Joined N.A. (R: 4.69, Z: 2.73) \\
\hline & & \multirow{3}{*}{$\begin{array}{l}\text { Greeted } \\
\text { neighbours on a } \\
\text { daily basis } \\
\text { (R: } 3.19, \mathrm{Z}: 2.96)\end{array}$} & $\begin{array}{l}\text { Problems of N.A. is conventionalization } \\
\text { and mannerism issue (R: } 3.88, \mathrm{Z}: 2.73)\end{array}$ \\
\hline & & & $\begin{array}{l}\text { Have experience in stairs committee } \\
\text { (R: } 3.52, \mathrm{Z}: 2.73 \text { ) }\end{array}$ \\
\hline & & & $\begin{array}{l}\text { Will participate in D.P. training if it is } \\
\text { convenient for them (R: } 3.00, \mathrm{Z}: 2.81)\end{array}$ \\
\hline
\end{tabular}


Nadhirah Nordin \& Hitoshi Nakamura

Social Capital Among Ageing Residents of Housing Complexes in Suburban Tokyo: The Case of Haraichi-Danchi and

Oyamadai-Danchi in Ageo City

$70 \mathrm{~s}$

More than 10

Joined N.A. (R: 2.76, Z: 2.73)

reliable persons Knows very well about activities of N.A.

(R: 4.41, Z: 2.96)

(R: 5.96, Z: 3.02)

Thought that N.A. is necessary

(R: 5.61, Z:2.77)

Activities of N.A. that they would like to

join is auspicious celebration ( $R$ : 3.60 ,

Z:2.73)

Have experience in stairs committee

(R: 3.84, Z: 2.73)

*N.A.: Neighbourhood association; D.P.: Disaster prevention; R: Adjusted residual value; Z: Z-value

$* 20$ s -30 s are working people; 10 s and below are not included since they are still dependent to their parents

Table 3: Summary of findings for both social capital in Oyamadai-danchi

\begin{tabular}{|c|c|c|c|}
\hline $\begin{array}{l}\text { Housing } \\
\text { Complexes }\end{array}$ & $\begin{array}{l}\text { Age } \\
\text { Groups }\end{array}$ & $\begin{array}{l}\text { Bonding Social } \\
\text { Capital }\end{array}$ & Bridging Social Capital \\
\hline \multirow[t]{10}{*}{$\begin{array}{l}\text { Oyamadai- } \\
\text { danchi }\end{array}$} & $\begin{array}{l}\text { Below } \\
30 \mathrm{~s}\end{array}$ & - & $\begin{array}{l}\text { Activities of neighbourhood association } \\
\text { that they would like to take part is child } \\
\text { rearing support (R: } 7.27, \mathrm{Z}: 2.73 \text { ) } \\
\text { No experience in stairs committee (R: } 3.58 \text {, } \\
\mathrm{Z}: 2.73 \text { ) }\end{array}$ \\
\hline & \multirow[t]{3}{*}{$\begin{array}{l}40 \mathrm{~s} \\
50 \mathrm{~s}\end{array}$} & \multirow{3}{*}{$\begin{array}{l}\text { Communication } \\
\text { exchanges are } \\
\text { based on family } \\
\text { relationship } \\
\text { (R: } 4.23, \mathrm{Z}: 2.96)\end{array}$} & $\begin{array}{l}\text { Does not join neighbourhood association } \\
\text { (R: } 2.81, \mathrm{Z}: 2.73 \text { ) }\end{array}$ \\
\hline & & & $\begin{array}{l}\text { No experience in stairs committee (R: } 2.94 \text {, } \\
\text { Z: } 2.73 \text { ) }\end{array}$ \\
\hline & & & $\begin{array}{l}\text { Have not participated in D.P. training (R: } \\
2.98, \mathrm{Z}: 2.77 \text { ) }\end{array}$ \\
\hline & \multirow[t]{4}{*}{$60 \mathrm{~s}$} & \multirow[t]{4}{*}{-} & $\begin{array}{l}\text { Expectation for neighbourhood association } \\
\text { activities is to held activities with peace of } \\
\text { mind (R: } 3.52 \text {, Z: } 2.73 \text { ) }\end{array}$ \\
\hline & & & $\begin{array}{l}\text { Expectation for neighbourhood association } \\
\text { activities is to enhance the welfare } \\
\text { activities (R: } 3.09, \mathrm{Z}: 2.73 \text { ) }\end{array}$ \\
\hline & & & $\begin{array}{l}\text { Have experience in stairs } \\
(\mathrm{R}: 3.02, \mathrm{Z}: 2.73)\end{array}$ \\
\hline & & & $\begin{array}{l}\text { Currently participating in volunteering } \\
\text { (R: } 4.04, \mathrm{Z}: 2.87 \text { ) }\end{array}$ \\
\hline & \multirow[t]{2}{*}{$70 \mathrm{~s}$} & $\begin{array}{l}\text { Several reliable } \\
\text { person } \\
(\mathrm{R}: 3.06, \mathrm{Z}: 2.96)\end{array}$ & $\begin{array}{l}\text { Expectation for N.A. activities is to } \\
\text { organize disaster/ crime prevention } \\
\text { activities (R: } 3.25, \mathrm{Z}: 2.73 \text { ) }\end{array}$ \\
\hline & & $\begin{array}{l}\text { Chatting with } \\
\text { neighbours } \\
\text { daily (R: } 3.37, \mathrm{Z} \text { : } \\
\text { 2.96) }\end{array}$ & $\begin{array}{l}\text { Activities of N.A. that they would like to } \\
\text { join is auspicious celebration (R: } 3.34, \mathrm{Z}: 2.73 \text { ) }\end{array}$ \\
\hline
\end{tabular}


PLANNING MALAYSIA

Journal of the Malaysia Institute of Planners (2018)

\section{DISCUSSION}

A general observation can be made based on the two housing complexes cross tabulations. For bonding social capital in both housing complexes, responses from the elderly group of the 60s have shown that they have at least one person to rely on while the 70s age group tended to have several reliable persons. This is because both of these age groups have sufficient social contact with their neighbours and significant association with them by greeting and chatting with their neighbours on a daily basis, hence having neighbours as their reliable persons.

As expected, when compared to the elderly groups, the middle-aged group in their 40s - 50s have shown less significant extent of social capital whereby in Haraichi-danchi, they have nobody to rely on and have experienced some trouble with their neighbours in the past. In contrast, the middle-aged people in Oyamadai-danchi have shown significant association for communication exchange with neighbours but only because they had family relationships. Moreover, the middle-aged group in both housing complexes have not participated in the neighbourhood association and in disaster prevention training. The middle-aged group in Oyamadai-danchi also have not had any experience in becoming members of the stairs committee.

A general trend could be observed for bridging social capital in both housing complexes. This has been reflected by people from the 60 s and 70 s age groups through high level of participation in the neighbourhood association, volunteering activities and experience becoming stairs committee. In the past, residents who were in the middle age groups tended to reside and settle in these types of housing complexes located in the suburbs, living together with their families and commuted daily to work in the nearest urban area, Tokyo. Over time, this middle-aged generation has gotten old; becoming part of the elderly group but still living in these housing complexes after their retirement, making them the majority of permanent residents who have stayed for the longer period. Hence, the elderly group who have been permanent residents in the housing complexes through their long period of stay have had the advantages to be fully aware about the activities happening in the housing complexes, while at the same time developing their social ties and having good social interaction by spending more time outdoors. Consequently, spending their free time outdoors is important for the elderly because they can develop and improve their social interactions and social bonds with new people, acquaintances or even someone that they already knew.

More positive association has been found for the activities that the residents wanted to take part in if the neighbourhood association helped to organize it. Middle-aged people in the 40s - 50s were interested in joining the summer festival whereas most of the elderly from the 70s age group were interested in joining the auspicious celebration, which is Japan's traditional 
Nadhirah Nordin \& Hitoshi Nakamura

Social Capital Among Ageing Residents of Housing Complexes in Suburban Tokyo: The Case of Haraichi-Danchi and

Oyamadai-Danchi in Ageo City

celebrations of longevity. This is relevant for the younger generation who are more interested to participate in fun activities and for the elderly who would benefit from spending their time in peaceful and calm activities such as the auspicious celebration.

Furthermore, most of the younger age group especially people in their 20 s - 30s tended to have less time to participate in bridging activities in both housing complexes due to the fact that they are mostly among the working people and usually have less time during the day. They tended to have free time only during weekday nights and weekends to spend time with their families. Most of them have less time to join the bridging activities because they are busy with working and parenting. People in this age group also hoped that the neighbourhood association could help with child rearing support as one of the expected activities, as they felt it was a burden for them to keep up with their working life while at the same time spending the time to care for their children.

Moreover, the older people from the 60s age group living in Haraichidanchi thought that the neighbourhood associations conducted conventional activities which made them feel burdened to join. This was supported by the observed data from the residents in Haraichi-danchi about the reasons for not wanting to join the neighbourhood association. The reasons include feeling obligated to be part of the stairs committee and burden to pay the membership fee in the neighbourhood association. The observed data also showed a different trend for the residents in Haraichi-danchi where quite a number of them did not know what the neighbourhood association was doing, when compared to the residents in Oyamadai-danchi.

In addition, a typical trend has been shown regarding the participation of the older people in social and community activities because they usually have extra time due to retirement and unemployment. The trend in Oyamadai-danchi was observed to adhere to this typical trend, but there was a worrying trend for the elderly in Haraichi-danchi where most people in the 60s and 70s age groups have not participated in the disaster prevention training. This was largely due to low awareness about the importance of disaster prevention training, whereby the observed data show most of them did not know about the existence of the voluntary disaster prevention organization even though they expected disaster prevention training should be done.

Generally, based on the research findings, the bonding social capital tended to show more positive associations in Haraichi-danchi but less positive associations for bridging social capital. This was due to the fact that Haraichidanchi is divided into two areas by an arterial highway. Residents living on the other part of the housing complex may tend to be less interested to join the bridging activities since it would take some efforts for them to cross the overhead bridge especially the elderly. The activities of bonding social capital may take place naturally among the residents, anywhere in the housing complex as it 
PLANNING MALAYSIA

Journal of the Malaysia Institute of Planners (2018)

involves basic daily social interaction but for bridging social capital, the activities are usually held in one part of the housing complex where the SIT satellite laboratory is located.

\section{CONCLUSION}

In conclusion, this research has achieved its purpose of distinguishing the features of elderly groups in Haraichi-danchi and Oyamadai-danchi. For bonding among elderly groups of 60s and 70s age group in both housing complexes, they have several reliable persons and have daily social contact with their neighbours as well as high level of participation in most social and community organizations, and they were most interested in joining the auspicious celebration if it was to be held by the neighbourhood associations. Additionally, elderly people in Oyamadai-danchi tended to participate in disaster prevention training, but elderly people in Harachi-danchi did not participate in disaster prevention training because they did not know about the existence of the voluntary disaster prevention organization. From this, further investigation on how to strengthen the bonding and bridging social capital especially among the groups of people in their $60 \mathrm{~s}$ and $70 \mathrm{~s}$ in both housing complexes by looking in terms of physical neighbourhood environment should be conducted.

\section{REFERENCES}

Aminjafari, B., Aghajani, H., \& Hashemianfar, A. (2016). A sociological explanation of active aging with emphasizing on social capital in Isfahan City. International Journal of Social Sciences, 6(3), 15-25.

Babaei, H., Ahmad, N., \& Gill, S. (2012). Bonding, bridging and linking social capital and empowerment among squatter settlements in Tehran, Iran. World Applied Sciences Journal, 17(1), 119 - 26.

Gouda, K., \& Okamoto, R. (2012). Current status of and factors associated with social isolation in the elderly living in a rapidly aging housing estate community. Environmental Health and Preventive Medicine, 17(6), 500 - 11.

Putnam, R. (2000) Bowling alone: The collapse and revival of American community. New York: Simon \& Schuster.

Szreter, S., \& Woolcock, M. (2004). Health by association? Social capital, social theory and the political economy of public health. International Journal of Epidemiology, $33(4), 650$ - 670.

Twigger-Ross, C., Bonaiuto, M., \& Breakwell, G. (2003). Identity theories and environmental psychology. In M. Bonnes, T. Lee, M. Bonaiuto (Eds), Psychological theories for environmental issues. Ashgate: Aldershot.

World Bank (2016). Data on population ages 65 years and above in Japan. Retrieved from https://data.worldbank.org/indicator/SP.POP.65UP.TO.ZS 